\title{
Treatment adherence among adult hypertensive patients: a cross-sectional retrospective study in primary care in Romania
}

This article was published in the following Dove Press journal:

Patient Preference and Adherence

\author{
Ioan Tilea' \\ Dorina Petra' \\ Septimiu Voidazan ${ }^{2}$ \\ Elena Ardeleanu ${ }^{3}$ \\ Andreea Varga'
}

'Department M3-Internal Medicine, Family Medicine Discipline, Faculty of Medicine, University of Medicine and Pharmacy, Tirgu Mures, Mures, Romania; ${ }^{2}$ Department M2-Functional and Complementary Sciences, Epidemiology Discipline, Faculty of Medicine, University of Medicine and Pharmacy, Tirgu Mures, Mures, Romania; ${ }^{3}$ Department XVIBalneology, Medical Rehabilitation and Rheumatology, Family Medicine Discipline, Faculty of Medicine, University of Medicine and Pharmacy, Timisoara, Timis, Romania
Correspondence: Dorina Petra Department M3-Internal Medicine, Family Medicine Discipline, Faculty of Medicine, University of Medicine and Pharmacy, 38, Gheorghe Marinescu Street, Tirgu Mures 540319,

Mures, Romania

Tel +40 74019 4I 22

Fax +40265211011

Email medfam.tgm@gmail.com
Purpose: This study was performed to elucidate the level of adherence to antihypertensive treatment in adult subjects attending a family medicine clinic in a city in central Romania.

Patients and methods: A cross-sectional, retrospective study was performed on a cohort of hypertensive adults. A total of 525 participants were selected from 1,714 adults attending a single urban family medicine practice. Assessment of adherence to therapy was performed by a chart review of prescription and clinical records over a 4-year study period.

Results: The results showed that $69.8 \%$ of the patients had high adherence ( $>80 \%$ with therapy); $20.3 \%$ had medium adherence $(20 \%-79 \%)$; and $9.9 \%$ had low adherence $(<20 \%)$. A positive association was found ( $p=0.01$ ) between low adherence and male gender. A significant positive association ( $p=0.02$ ) was found between total cardiovascular risk and level of adherence. We found that $54.7 \%$ of the high adherence subjects had well-controlled blood pressure, and chronic kidney disease was associated with high adherence to therapy $(p=0.03)$. Antihypertensive regimens administered as fixed-dose combinations were positively associated with high adherence ( $p=0.001)$. Subjects who had their antihypertensive regimen adjusted to a new drug class during the study period showed enhanced adherence compared to subjects treated with an unchanged regimen $(p=0.001)$.

Conclusion: This is the first published study assessing adherence to antihypertensive therapy in family medicine practice in Romania. It presented data derived from a primarily urban setting and targeted a geographical area where the prevalence of hypertension has increased continuously. Female gender, age, presence of cardiovascular risk factors, defined cardiovascular disease, chronic renal impairment, and good control of hypertension were positively associated with high adherence. The results provide insights to guide further strategies to improve adherence and indirect methods for blood pressure management strategies.

Keywords: blood pressure, family medicine, hypertension, prescription, Eastern Europe

\section{Introduction}

The global prevalence of high blood pressure (BP) in adults aged 18 years and older is $31.1 \%{ }^{1}$

Compared to developed countries, in low-to-middle-income countries, the incidence of hypertension (HTN) is increased, and awareness, treatment, and control of the disease are at low levels. ${ }^{1}$ The Study for the Evaluation of Prevalence of HTN and Cardiovascular (CV) Risk in Romania (SEPHAR II) was designed to identify and characterize the profile of Romanian hypertensive patients. The results revealed a prevalence of HTN in the Romanian population of $40.41 \%$ and that proper control of BP was maintained in one-quarter of the hypertensive subjects. ${ }^{2}$ The SEPHAR III study 
in 2017 then showed an increased prevalence of HTN, despite increased awareness, treatment, and attempted control of the disease. It is estimated that by 2020 the prevalence of HTN will increase to $44 \%$ with treatment control of $36.6 \%$. 3,4

Supporting the conclusions of the SEPHAR II and III studies, population-based analyses of prevention, diagnosis, and treatment of HTN have identified a high prevalence of uncontrolled HTN. Even in high-income countries such as Switzerland, the rate of BP control in hypertensive patients is $40.8 \%$, and nonadherence with treatment is high. ${ }^{5}$ Improving HTN management by strategies that are feasible in typical health care settings is essential.

The Systolic BP Intervention Trial (SPRINT) demonstrated the importance of intensive BP control for reducing the incidence of stroke, acute coronary syndrome, myocardial infarction, congestive heart failure, and CV death. ${ }^{6}$ The number of years of life and adjusted quality of life is higher in patients undergoing intensive treatment, and this trend persists throughout their lifespan. ${ }^{7}$ Optimal therapy requires efficient treatment strategies together with high adherence to the antihypertensive regimen. Low adherence to treatment is an obstacle to effective therapy of HTN and leads to poor prognoses, increased days of hospitalization, and higher death rates. ${ }^{8}$

Although Oung et $\mathrm{al}^{9}$ found that adherence to treatment is better in patients with HTN compared to other chronic diseases, good compliance with antihypertensive therapy is a multifactorial process. It is influenced by environmental factors, as well as the type of treatment (including dosing regimen), concomitant medications, clinical status, presence of comorbidities, cost of treatment, and the doctor-patient relationship. ${ }^{10,11}$ In addition, in older hypertensive patients, high adherence to their prescribed pharmacotherapy is associated with low $\mathrm{CV}$ risk. ${ }^{12}$

Pirasath et $\mathrm{al}^{13}$ emphasized that noncompliance with the prescribed medication regimen and interruptions in daily routine are the most common reasons for non-adherence among hypertensive patients with their treatment plans.

The marked heterogeneity of results in studies on adherence to therapy in hypertensives reflects the multiple available assessment methods (subjective, indirect, and direct) utilized. $^{14}$

Although the retrospective evaluation of drug prescription records offers a novel strategy for the assessment of adherence to pharmacotherapy, ${ }^{15}$ an European panel of experts recommends a combination of methods for measuring adherence, combining electronic monitoring and drug-level measurements. Parati et $\mathrm{al}^{16}$ advocated home-based BP telemonitoring to improve adherence to therapy. Noninvasive adherence assessment methods, such as the use of digital medicine drugs (ingestible sensors incorporated into pills), was used by Frias et $a{ }^{17}$ for real-time (dose-by-dose) feedback about treatment adherence in hypertensive type 2 diabetic patients.

In addition, the quality of communication, with high levels of patient education conferring greater knowledge and understanding of the disease and its complications, can improve adherence to antihypertensive therapy. ${ }^{18,19}$ A strategy involving dynamic physician-patient collaboration, along with increased involvement of pharmacists to support the treatment goals and motivate patients, can improve adherence to therapy. ${ }^{20}$ This is important because inadequate control of HTN is associated with excessive use of medical resources and elevated $\mathrm{CV}$ risks.

The limited availability of data regarding adherence to antihypertensive treatment in Eastern Europe, including Romania, led to the current study, which was designed to elucidate the level of adherence to antihypertensive treatment in patients from an urban area family medicine practice.

\section{Patients and methods}

A cross-sectional, descriptive study was carried out by prescreening records from 1,714 adult patients followed-up in a family medicine practice in Tirgu Mures, a city in central Romania, Eastern Europe. Medical records for visits between January 2011 and December 2014 were reviewed, and 525 subjects were selected and enrolled as subjects in the study. Recruitment for active participation in the study was conducted by phone call invitations or by personal invitations during planned appointments or medical checkups.

Patients meeting the following criteria were considered for enrollment in the study:

- Age older than 18 years, irrespective of gender

- Having a diagnosis of HTN (according to the 2013 European Society of HTN [ESH]/European Society of Cardiology [ESC] guidelines for the management of arterial HTN $)^{21}$ and pharmacotherapy regimen for their BP for a minimum of 3 months before entry into the study

- Newly diagnosed hypertensive patients initiated on medication that continued for at least 3 consecutive months.

A total of 459 subjects $(87.4 \%)$ were previously diagnosed with HTN, and 66 (12.6\%) were diagnosed with it during the study period. Patients unable to give informed consent were excluded.

\section{Ethical considerations}

The study project was reviewed and approved by the ethics committee for scientific research of the University of Medicine and Pharmacy of Tirgu Mures, Romania (no 94/2015). 
According to the Declaration of Helsinki, each study participant signed a document indicating written informed consent. Authors maintained the confidentiality of each of the subject's data and limited authorized access via a passwordprotected computer system was available.

\section{Data collection}

Data were retrospectively collected from the available paper files and electronic recordings by a multidisciplinary medical team (consisting of general practitioners and cardiologists).

Data were extracted from Pharmec ${ }^{\odot}$ Healthcare Software, v 6.0; 2014; Cegedim RX/Pharmec Healthcare Software, Romania, which is a dedicated electronic medical record (EMR) software package for family physicians and pharmacies in Romania. The patients data were compiled using a Microsoft Excel $^{\odot}$ spreadsheet (Microsoft ${ }^{\circledR}$ Office 2013; Microsoft Corporation, Redmond, WA, USA). Sociodemographic characteristics (age, gender, marital status, education, urban/rural residence), clinical characteristics (height, weight, body mass index, BP measurements, comorbidities), antihypertensive drug class and adherence, and/or persistence assessment data for each patient were added to the Excel database.

Participants were divided into three groups:

1. Active follow-up: prescriptions consecutively dispensed over the 48 months of the study

2. Lost to follow up: failed to comply with the treatment plan during the course of the study and/or did not return during the study for new prescriptions

3. Deceased during the course of the study: that still had regularly dispensed prescriptions for antihypertensive medications up to the time of death.

Different variables were analyzed:

- Age: six major groups: $\leq 40,41-50,51-60,61-70$, $71-80$, and $>80$ years old

- Level of formal education: none, primary school graduate, secondary/high school graduate, and university graduate

- Total CV risk

- Presence of cardiovascular disease (CVD) defined by confirmed ischemic heart disease (angina pectoris, previous myocardial infarction, or any type of myocardial revascularization), valvular heart disease, cardiomyopathy, and peripheral or carotid artery disease

- Presence of chronic kidney disease (CKD)

- Concomitant type 2 diabetes mellitus (DM).

An indirect, noninvasive method for adherence assessment was used, specifically, a prescription record review. This was performed by computing the total number of consecutive months that had been covered by antihypertensive prescriptions, during the 48-month study. Adherence was expressed as a percentage of time, with the first month taken into account was January 2011 and the last counted month, continuously covered by prescription, was December 2014.

Three levels of adherence were documented: low $(<20 \%)$, medium $(20 \%-79 \%)$, and high $(\geq 80 \%)$; each subject was graded by their percentage of adherence by the three different levels as defined earlier.

Persistence with the antihypertensive regimen was defined by maintenance of a specific antihypertensive drug class during the study period. Any changes in the antihypertensive prescriptions written for the subjects during the 4-year study were checked by analyzing the medical records available on paper charts as well as the EMR. One hypertensive patient was utilizing herbal products for treatment. Consequently, the patient was excluded from statistical analyses of adherence.

Uncontrolled BP for the nondiabetic subjects was defined as systolic $\mathrm{BP}>140 \mathrm{mmHg}$ and/or diastolic $\mathrm{BP}>90 \mathrm{mmHg}$, and for the diabetics as systolic $\mathrm{BP}>130 \mathrm{mmHg}$ and diastolic $\mathrm{BP}>80 \mathrm{mmHg}$. BP was measured using an automatic device (Omron M3 Comfort, HEM-7134-E; Omron Healthcare, Co., Ltd., Japan) certified by ESH, International Protocol revision 2010, for the validation of BP-measuring devices in adults, to the standards of the 2013 ESH guidelines. ${ }^{22} \mathrm{BP}$ measurement was included in all routine medical visits and was followed routinely by appropriate treatment with BP-lowering drugs when HTN was diagnosed. Patients diagnosed with HTN returned to their family physician for further monitoring and prescriptions of BP-lowering medications every month or within 2 or 3 months according to the clinical findings and treatment plan. All BP measurements recorded in the EMR and paper chart notes were computed.

\section{Statistical analyses}

Statistical analyses were carried out using SPSS for Windows (v 22.0; IBM Corporation, Armonk, NY, USA) and MedCalc (v 10.3.0.0; MedCalc Software, Ostend, Belgium) software programs. The Kolmogorov-Smirnov test was used to assess the normal distribution of continuous numerical variables. The results were presented as numbers and percentages for qualitative variables. Data were compared using the chisquared test. For correlation, Pearson coefficients were used. A value of $p<0.05$ was considered statistically significant.

\section{Results}

\section{Patient characteristics and overall adherence evaluation}

Baseline sociodemographic data of 525 stratified hypertensive patients, both overall and in subgroups (active, deceased, 
and lost to follow-up), are listed in Table 1 . The mean age of all the subjects was $62.1 \pm 12.3$ years; for active patients, it was $61.5 \pm 11.9$ years.

Male subjects did not adhere to the treatment plan in $80.4 \%$ of the cases and thus were poorly adherent $(<20 \%)$ to the antihypertensive therapy $(p=0.01)$. We found no statistically significant trends regarding the residence area $(p=0.07)$, marital status $(p=0.06)$, or professional background of the subjects $(p=0.11)$.

\section{CV risk factors, comorbidities, and adherence}

Total $\mathrm{CV}$ risk evaluation among the active hypertensive subjects found $32.2 \%$ at high risk and $32.4 \%$ at very high CV risk. There was no positive statistical association $(p=0.46)$ with active versus deceased hypertensive subjects.

Comparing the subjects at moderate $\mathrm{CV}$ risk with low adherence $(42.9 \%)$ to those at very high $\mathrm{CV}$ risk with medium and high levels of adherence $(32.3 \%$ and $34.6 \%$, respectively), a significant positive association $(p=0.02)$ between total $\mathrm{CV}$ risk and level of adherence was identified (Table 2). In addition, when the active and deceased subject groups were compared, no statistically significant association between the level of adherence and the total CV risk was found $(p=0.10)$.
Not surprisingly, medication adherence was related to BP control, as shown by the significant differences seen over the three levels of adherence $(p=0.002)$. A significant association was found between low adherence $(<20 \%)$ and uncontrolled BP. However, in the high ( $\geq 80 \%)$ adherence group, only $54.7 \%$ of the subjects had documented control of their BP (Figure 1).

Concomitant presence of DM did not significantly affect the statistical likelihood of a low, medium, or high adherence $(p=0.07)$. However, the presence of established CVD was associated with high adherence to antihypertensive treatment $(p=0.03)$. For the subjects with CKD and HTN, the presence of different stages of renal damage did not appear to influence the level of adherence ( $p=0.24)$. With respect to the hypertensive subjects with CKD and lower levels of estimated glomerular filtration rate (eGFR; $<60 \mathrm{~mL} / \mathrm{min} / 1.73 \mathrm{~m}^{2}$ ) consistent with advancing renal failure, there was evidence of increased adherence (23.3\%) as opposed to low adherence (11.8\%). Thus, comparing the different subsets presenting CVD associated either with DM or CKD, we concluded that the presence of CKD with eGFR $<60 \mathrm{~mL} / \mathrm{min} / 1.73 \mathrm{~m}^{2}$ is associated with high adherence to antihypertensive therapy $(p=0.03)$. However, in patients presenting with CVD with CKD and DM, there was no overall association between the three levels of adherence ( $p=0.08$; Table 3$)$.

Table I Sociodemographic characteristics of 525 participants, family medicine practice cohort

\begin{tabular}{|c|c|c|c|c|c|c|c|c|}
\hline \multirow[t]{2}{*}{ Demographics } & \multicolumn{2}{|c|}{$\begin{array}{l}\text { Total } \\
(n=525) ; 100 \%\end{array}$} & \multicolumn{2}{|c|}{$\begin{array}{l}\text { Active participants } \\
(\mathrm{n}=485) ; 92.4 \%\end{array}$} & \multicolumn{2}{|c|}{$\begin{array}{l}\text { Deceased } \\
(n=31) ; 5.9 \%\end{array}$} & \multicolumn{2}{|c|}{$\begin{array}{l}\text { Lost to follow up } \\
(n=9) ; 1.7 \%\end{array}$} \\
\hline & Total & $\%$ & Total & n (\%) & Total & n (\%) & Total & n (\%) \\
\hline \multicolumn{9}{|l|}{ Gender } \\
\hline Male & 321 & 61.1 & 292 & $91.0(60.2)$ & 23 & $7.2(74.2)$ & 6 & $1.9(66.7)$ \\
\hline Female & 204 & 38.9 & 193 & $94.6(39.8)$ & 8 & $3.9(25.8)$ & 3 & I.5 (33.3) \\
\hline \multicolumn{9}{|l|}{ Age (years) } \\
\hline$\leq 40$ & 23 & 4.4 & 21 & 91.3 (4.3) & 0 & $0.0(0.0)$ & 2 & $8.7(22.2)$ \\
\hline $4 I-50$ & 68 & 13.0 & 65 & $95.6(13.4)$ & I & $1.5(3.2)$ & 2 & $2.9(22.2)$ \\
\hline $5 I-60$ & 150 & 28.6 & 145 & $96.7(29.6)$ & 4 & $2.7(12.9)$ & I & $0.7(11.1)$ \\
\hline $6 \mathrm{I}-70$ & 140 & 26.7 & 129 & $92.1(26.6)$ & 9 & $6.4(29.0)$ & 2 & I.4 (22.2) \\
\hline $7 \mid-80$ & 107 & 20.4 & 97 & $90.7(20.0)$ & 8 & $7.5(25.8)$ & 2 & $1.9(22.2)$ \\
\hline$>80$ & 37 & 7.0 & 28 & 75.7 (5.8) & 9 & $24.3(29.0)$ & 0 & $0.0(0.0)$ \\
\hline \multicolumn{9}{|l|}{ Marital status } \\
\hline Married & 404 & 77.0 & 374 & $92.6(77.1)$ & 22 & $5.4(71.0)$ & 8 & $2.0(88.9)$ \\
\hline Divorced & 15 & 2.9 & 13 & $86.7(2.7)$ & 2 & I3.0 (6.5) & 0 & $0.0(0.0)$ \\
\hline Unmarried & 17 & 3.2 & 17 & 100.0 & 0 & $0.0(0.0)$ & 0 & $0.0(0.0)$ \\
\hline Widowed & 89 & 17.0 & 81 & 91.0 (16.7) & 7 & $7.9(22.6)$ & I & I.I (II.I) \\
\hline \multicolumn{9}{|l|}{ Educational grade } \\
\hline None & 3 & 0.6 & 0 & $0.0(0.0)$ & 3 & $100.0(9.7)$ & 0 & $0.0(0.0)$ \\
\hline Primary school & 5 & 1.0 & 4 & $80.0(0.8)$ & 0 & $0.0(0.0)$ & I & $20.0($ II.I) \\
\hline Secondary/high school & 302 & 57.5 & 281 & $93.0(57.9)$ & 16 & $5.3(51.6)$ & 5 & $1.7(55.6)$ \\
\hline University graduate & 215 & 41.0 & 200 & $93.0(4 \mid .2)$ & 12 & $5.6(38.7)$ & 3 & I.4 (33.3) \\
\hline \multicolumn{9}{|l|}{ Residence area } \\
\hline Urban & 467 & 89.0 & 434 & $92.9(89.5)$ & 27 & $5.8(87.1)$ & 6 & I.3 (66.7) \\
\hline Rural & 58 & 11.0 & 51 & $87.9(10.5)$ & 4 & $6.9(12.9)$ & 3 & $5.2(33.3)$ \\
\hline
\end{tabular}


Table 2 Treatment adherence and CV risk

\begin{tabular}{|c|c|c|c|c|c|}
\hline \multirow[t]{2}{*}{ Patient group } & \multirow[t]{2}{*}{ CV risk stratification } & \multicolumn{3}{|c|}{ Adherence, n (\%) } & \multirow{2}{*}{$\begin{array}{l}\text { Total } \\
\text { patients, n (\%) }\end{array}$} \\
\hline & & $<\mathbf{2 0}$ & $20-79$ & $\geq 80$ & \\
\hline \multirow[t]{7}{*}{ Active patients $(p=0.02)$} & $\mathrm{CV}$ risk stratification & & & & \\
\hline & None & $0(0.0)$ & $0(0.0)$ & $3(0.9)$ & $3(0.6)$ \\
\hline & Low & $4(9.5)$ & $13(13.1)$ & $19(5.5)$ & $36(7.4)$ \\
\hline & Moderate & $18(42.9)$ & $29(29.3)$ & $86(25.0)$ & $133(27.4)$ \\
\hline & High & $14(33.3)$ & $25(5.3)$ & $117(34.0)$ & $156(32.2)$ \\
\hline & Very high & $6(14.3)$ & $32(32.3)$ & $119(34.6)$ & $157(32.4)$ \\
\hline & Total & $42(100.0)$ & $99(100.0)$ & $344(100.0)$ & $485(100.0)$ \\
\hline \multirow[t]{6}{*}{ Deceased patients $(p=0.55)$} & $\mathrm{CV}$ risk stratification & & & & \\
\hline & Low & $0(0.0)$ & $0(0.0)$ & $\mathrm{I}(6.2)$ & I (3.2) \\
\hline & Moderate & $0(0.0)$ & $2(33.3)$ & $3(18.8)$ & $5(16.1)$ \\
\hline & High & $4(44.4)$ & I (I6.7) & $7(43.8)$ & $12(38.7)$ \\
\hline & Very high & $5(55.6)$ & $3(50.0)$ & $5(31.2)$ & $13(41.9)$ \\
\hline & Total & $9(100.0)$ & $6(100.0)$ & $16(100.0)$ & $31(100.0)$ \\
\hline \multirow[t]{7}{*}{ Total patients $(p=0.10)$} & $\mathrm{CV}$ risk stratification & & & & \\
\hline & None & $0(0.0)$ & $0(0.0)$ & $3(0.8)$ & $3(0.6)$ \\
\hline & Low & $4(7.8)$ & $13(12.4)$ & $20(5.6)$ & $37(7.2)$ \\
\hline & Moderate & $18(35.3)$ & $31(29.5)$ & $89(24.7)$ & $138(26.7)$ \\
\hline & High & $18(35.3)$ & $26(24.8)$ & $124(34.4)$ & $168(32.6)$ \\
\hline & Very high & II (2I.6) & $35(33.3)$ & $124(34.4)$ & 170 (32.9) \\
\hline & Total & $51(100.0)$ & $105(100.0)$ & $360(100.0)$ & $516(100.0)$ \\
\hline
\end{tabular}

Abbreviation: $\mathrm{CV}$, cardiovascular.

\section{HTN pharmacotherapy and adherence}

Regarding adherence to the different drug classes prescribed for the subjects (Table 4), angiotensin receptor blockers (ARBs) demonstrated very significant values for all three levels of adherence ( $p=0.001)$. Statistical significance also occurred with angiotensin-converting enzyme inhibitors (ACEI; $p=0.001)$, beta-blockers ( $p=0.001)$, and calcium channel blockers $(p=0.002)$. However, there were no significant associations detected for adherence to diuretics $(p=0.16)$ or centrally acting antihypertensive drugs $(p=0.81)$.

Assessing the adherence to antihypertensive treatment administered as fixed-dose combinations (FDCs), we found a very significant adherence rate $(p=0.001)$. This association was not present at the beginning of the study, in $2011(p=0.16)$.

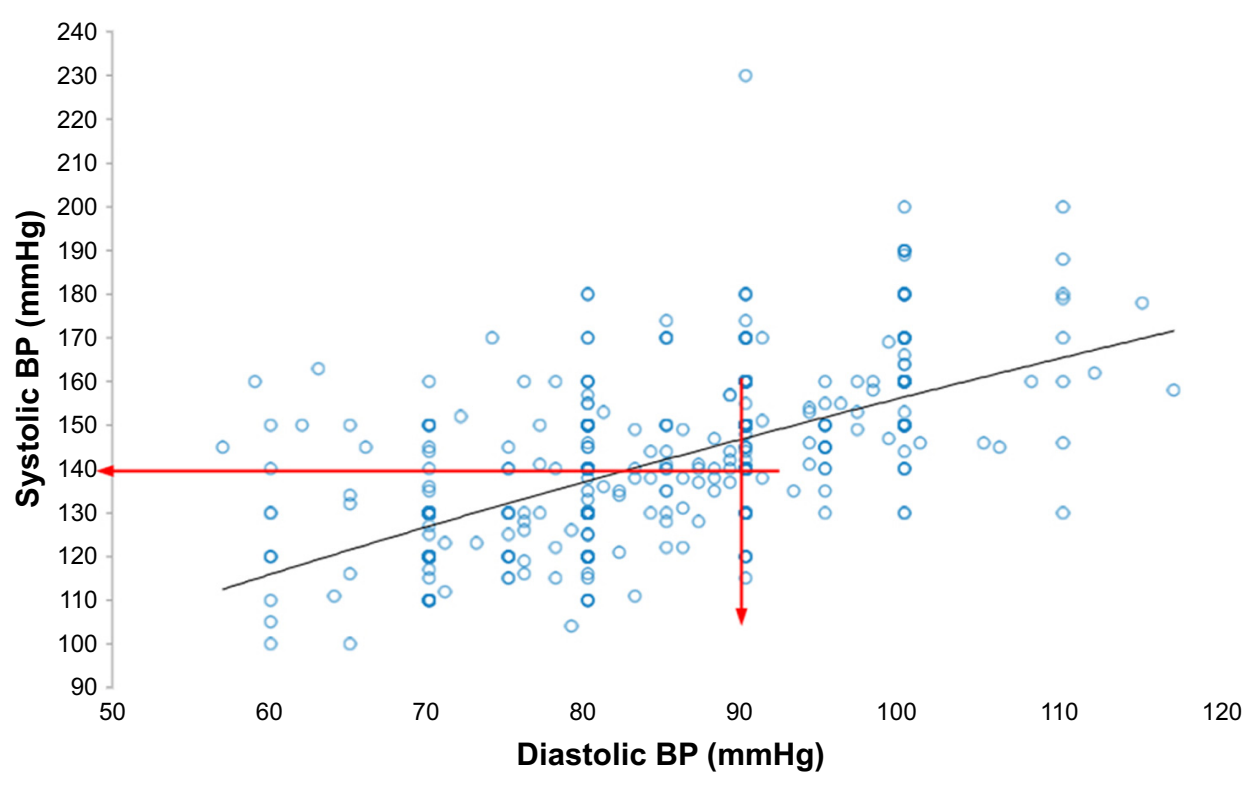

Figure I Participants' BP control/risk factors - uncontrolled BP.

Notes: The red line establishes the cut-off value for controlled and uncontrolled BP. The blue circles represent the individual BP value for each and every patient. The black line represents the trend in the systolic BP.

Abbreviation: BP, blood pressure. 
Table 3 Treatment adherence and comorbidities

\begin{tabular}{|c|c|c|c|c|c|}
\hline \multirow{2}{*}{$\begin{array}{l}\text { Hypertensive } \\
\text { participants' } \\
\text { comorbidities }\end{array}$} & \multirow{2}{*}{$\begin{array}{l}p \text {-value } \\
\text { trend }\end{array}$} & \multicolumn{3}{|c|}{ Adherence } & \multirow{2}{*}{$\begin{array}{l}\text { Total } \\
\text { patients, } \\
\text { n (\%) }\end{array}$} \\
\hline & & $\begin{array}{l}<20 \\
\text { n (\%) }\end{array}$ & $\begin{array}{l}\text { 20-79, } \\
\text { n (\%) }\end{array}$ & $\begin{array}{l}\geq 80, \\
\text { n (\%) }\end{array}$ & \\
\hline \multicolumn{6}{|l|}{ DM } \\
\hline Presence & 0.07 & $5(9.8)$ & $25(23.8)$ & $86(23.6)$ & $116(22.5)$ \\
\hline Absence & & $46(90.2)$ & $80(76.2)$ & $274(76.1)$ & $400(77.5)$ \\
\hline \multicolumn{6}{|l|}{ CVD } \\
\hline Presence & 0.03 & $34(66.7)$ & $73(69.5)$ & $286(79.4)$ & $393(76.2)$ \\
\hline Absence & & $17(33.3)$ & $32(30.5)$ & $74(20.6)$ & $123(23.8)$ \\
\hline \multicolumn{6}{|c|}{$\mathrm{eGFR}<60, \mathrm{~mL} / \mathrm{min} / \mathrm{I}, 73 \mathrm{~m}^{2}$} \\
\hline Presence & 0.03 & $6(11.8)$ & $15(14.3)$ & $84(23.3)$ & $105(20.3)$ \\
\hline Absence & & $45(88.2)$ & $90(85.7)$ & $276(76.7)$ & $4 I I(79.7)$ \\
\hline \multicolumn{6}{|l|}{ eGFR $<60+D M$} \\
\hline Presence & 0.08 & $0(0.0)$ & $3(2.9)$ & $23(6.4)$ & $26(5.0)$ \\
\hline Absence & & $51(100 \%)$ & $102(97.1)$ & $337(93.6)$ & $490(95.0)$ \\
\hline \multicolumn{6}{|l|}{$C V D+C K D$} \\
\hline Presence & 0.04 & $5(9.8)$ & $14(13.3)$ & $78(21.7)$ & $97(18.8)$ \\
\hline Absence & & $46(90.2)$ & 91 (86.7) & $282(78.3)$ & $419(81.2)$ \\
\hline \multicolumn{6}{|c|}{$C V D+C K D+D M$} \\
\hline Presence & 0.08 & $0(0.0)$ & $3(2.9)$ & $22(6.1)$ & $25(4.8)$ \\
\hline Absence & & $51(100.0)$ & $102(97.1)$ & $338(93.9)$ & $491(95.2)$ \\
\hline \multicolumn{6}{|l|}{$C V D+D M$} \\
\hline Presence & 0.17 & $5(9.8)$ & $22(21.0)$ & $75(20.8)$ & $102(19.8)$ \\
\hline Absence & & $46(90.2)$ & $83(79.0)$ & $285(79.2)$ & $4 \mid 4(80.2)$ \\
\hline
\end{tabular}

Abbreviations: CKD, chronic kidney disease; CVD, cardiovascular disease; DM, diabetes mellitus; eGFR, estimated glomerular filtration rate (MDRD formula); MDRD, Modification of Diet in Renal Disease.
However, interventions based on FDC drug class during all 4 years of study demonstrated significantly high adherence to antihypertensive treatment compared to interventions with single agents from the same drug classes $(p=0.02)$. Even stronger adherence to antihypertensive treatment was observed for the FDC agents versus antihypertensive medications that were recommended from different drug classes $(p=0.001)$.

\section{Persistence with antihypertensive drug therapy from different classes}

Persistence of the use of different antihypertensive drug classes was analyzed by computing and comparing the percentage of subjects receiving the specific drug class in two different phases of our study: the first phase occurred at the beginning of data collection during January 2011, and the second occurred at the end of the study in December 2014. For the ARBs, "plateau utilization" occurred, with no significant changes over time, representing $28.5 \%$ of prescriptions in 2011 and $29.5 \%$ in 2014 . In contrast, the rate of calcium channel blocker usage changed over the 48-month study, increasing from $23.6 \%$ to $36.4 \%$. Figure 2 shows the dynamic

Table 4 Treatment adherence and antihypertensive drug classes

\begin{tabular}{|c|c|c|c|c|c|c|c|c|c|c|}
\hline \multirow{2}{*}{$\begin{array}{l}\text { Antihypertensive drug } \\
\text { class }\end{array}$} & \multirow{2}{*}{$\begin{array}{l}\text { Total } \\
\text { patients, } \\
\text { n (\%) }\end{array}$} & \multicolumn{3}{|c|}{$20 \mathrm{II}$, level of adherence } & \multirow{2}{*}{$\begin{array}{l}p \text {-value } \\
\text { trend }\end{array}$} & \multirow{2}{*}{$\begin{array}{l}\text { Total } \\
\text { patients, } \\
\text { n (\%) }\end{array}$} & \multicolumn{3}{|c|}{2014 , level of adherence } & \multirow{2}{*}{$\begin{array}{l}p \text {-value } \\
\text { trend }\end{array}$} \\
\hline & & $\begin{array}{l}<20 \\
\text { n (\%) }\end{array}$ & $\begin{array}{l}\text { 20-79, } \\
\text { n (\%) }\end{array}$ & $\begin{array}{l}\geq 80, \\
\text { n (\%) }\end{array}$ & & & $\begin{array}{l}<20, \\
\text { n (\%) }\end{array}$ & $\begin{array}{l}\text { 20-79, } \\
\text { n (\%) }\end{array}$ & $\begin{array}{l}\geq 80, \\
\text { n (\%) }\end{array}$ & \\
\hline \multicolumn{11}{|l|}{ ARB } \\
\hline Administered & I 38 (28.5) & $7(17.1)$ & $22(22.2)$ & $109(3 \mid .7)$ & 0.001 & $143(29.5)$ & $3(7.3)$ & $27(27.3)$ & $113(32.8)$ & 0.0012 \\
\hline Not administered & $34 I(70.5)$ & $29(70.7)$ & $0(0.0)$ & $0(0.0)$ & & $328(67.8)$ & $26(63.4)$ & 71 (7I.7) & $231(67.2)$ & \\
\hline Abandoned & $5(1.0)$ & $5(12.2)$ & 77 (77.8) & $235(68.3)$ & & $13(2.7)$ & $12(29.3)$ & $\mathrm{I}(\mathrm{I} .0)$ & $0(0.0)$ & \\
\hline \multicolumn{11}{|l|}{ ACEI } \\
\hline Administered & $265(54.8)$ & $16(39.0)$ & $56(56.6)$ & $193(56.1)$ & 0.11 & $273(56.4)$ & $13(3 \mid .7)$ & $58(58.6)$ & $202(58.7)$ & 0.001 \\
\hline Not administered & $219(45.2)$ & $25(6 I .0)$ & $43(43.4)$ & I5I (43.9) & & $211(43.6)$ & $28(68.3)$ & $4 I(4 I .4)$ & I 42 (4|.3) & \\
\hline \multicolumn{11}{|l|}{ BB } \\
\hline Administered & $209(43.2)$ & $9(22.0)$ & $42(42.4)$ & $158(45.9)$ & 0.01 & $242(50.0)$ & $8(19.5)$ & $49(49.5)$ & $185(53.8)$ & 0.001 \\
\hline Not administered & $275(56.8)$ & $32(78.0)$ & $57(57.6)$ & $186(54.1)$ & & $242(50.0)$ & $33(80.5)$ & $50(50.5)$ & $159(46.2)$ & \\
\hline \multicolumn{11}{|l|}{$\mathrm{CCB}$} \\
\hline Administered & II $4(23.6)$ & $5(12.2)$ & $13(13.1)$ & $96(27.9)$ & 0.002 & $176(36.4)$ & $6(14.6)$ & $29(29.3)$ & II 4 (4I.0) & 0.002 \\
\hline Not administered & $370(76.4)$ & $36(87.8)$ & $86(86.9)$ & $248(72.1)$ & & $308(63.6)$ & $35(85.4)$ & $70(70.7)$ & $203(59.0)$ & \\
\hline \multicolumn{11}{|l|}{ Diuretics } \\
\hline Administered & $236(48.8)$ & $15(36.6)$ & $45(45.5)$ & $176(51.2)$ & 0.16 & $293(60.5)$ & $18(43.9)$ & $58(58.6)$ & $217(63.1)$ & 0.052 \\
\hline Not administered & $248(51.2)$ & $26(63.4)$ & $54(54.5)$ & $168(48.8)$ & & 191 (39.5) & $23(56.1)$ & $4 I(4 I .4)$ & $127(36.9)$ & \\
\hline \multicolumn{11}{|l|}{ Central antihypertensive class } \\
\hline Administered & $2 I(4.3)$ & I (2.4) & $5(5.1)$ & $15(4.4)$ & 0.81 & $29(6.0)$ & I (2.4) & $8(8.1)$ & $20(5.8)$ & 0.43 \\
\hline Not administered & $463(95.7)$ & $40(97.6)$ & 94 (94.9) & $329(95.6)$ & & $455(94.0)$ & $40(97.6)$ & 91 (91.9) & $324(94.2)$ & \\
\hline \multicolumn{11}{|l|}{ FDCs } \\
\hline Administered & $90(18.6)$ & II (26.8) & $24(24.2)$ & $55(0 \mid 6.0)$ & 0.16 & $173(35.7)$ & I3 (3I.7) & $38(38.4)$ & $122(35.5)$ & 0.001 \\
\hline Not administered & $94(19.4)$ & $5(12.2)$ & $17(17.2)$ & $72(20.9)$ & & $9(1.9)$ & $0(0.0)$ & $3(3.0)$ & $6(1.7)$ & \\
\hline Abandoned & NA & NA & NA & NA & & $5(1.0)$ & $4(9.8)$ & $\mathrm{I}(\mathrm{I} .0)$ & $0(0.0)$ & \\
\hline Never treated with FDC & $300(62.0)$ & $25(6 I .0)$ & $58(58.6)$ & $217(63.1)$ & & $297(61.4)$ & $24(58.5)$ & $57(57.6)$ & $216(62.8)$ & \\
\hline
\end{tabular}

Abbreviations: ACEl, angiotensin-converting enzyme inhibitors; ARB, angiotensin receptor blocker; BB, beta-blockers; CCB, calcium channel blocker; FDC, fixed-dose combination; NA, not applicable. 


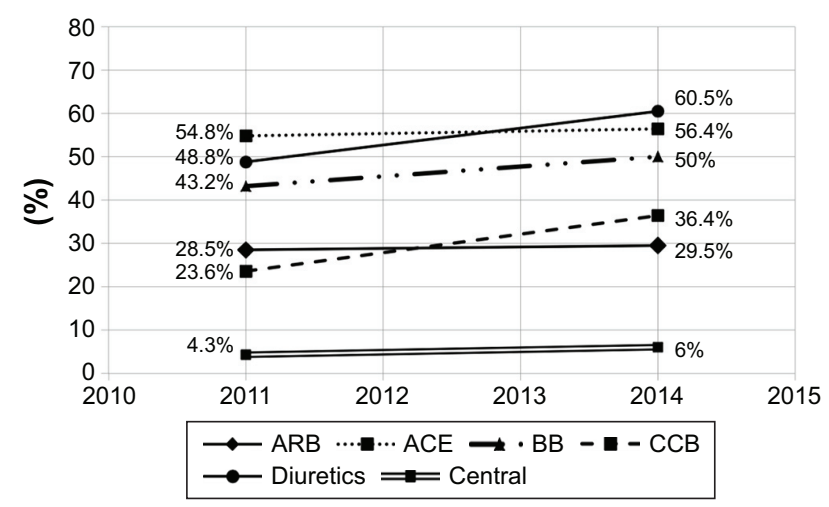

Figure 2 Persistence with antihypertensive drug classes.

Abbreviations: $A R B$, angiotensin receptor blocker; $B B$, beta-blockers; $C C B$, calcium channel blocker; ACE, angiotensin-converting enzyme inhibitor.

of persistence with each antihypertensive drug class which was analyzed one by one in the study.

With regard to "statin" usage in these hypertensive subjects, there was a significant increase in the rate that these agents were prescribed $(p=0.04)$ over the 4 years of the study.

\section{Discussion}

In our hypertensive subject population, $69.8 \%$ had high adherence (above $80 \%$ ), 20.3\% had medium adherence $(20 \%-79 \%)$, and $9.9 \%$ had low adherence $(<20 \%)$ with respect to the usage of the prescribed medications. Comparable levels of medium-to-high adherence were reported for a group of 2,128 patients in the US (62.5\%) during a 4-year study. ${ }^{19}$ Additional results of similar magnitude were obtained in other studies in American, Jordanian, and Ethiopian patients. ${ }^{9,10,23}$

However, some studies report high levels of nonadherence to antihypertensive treatment. In a cross-sectional study performed in Ghana and Nigeria, $66.7 \%$ of the patients were non-adherent to treatment. Non-adherence was related to age (younger patients) and education level. ${ }^{24}$

Identifying the factors that can influence adherence to antihypertensive therapy may help improve planning and development of individualized programs for treatment. Thus, the factors associated with increased adherence to therapy are correlated with: gender (female), race (white), marital status (married), age, educational attainment, socioeconomic, and cultural level (higher). ${ }^{25-27}$ In comparison to the elderly, younger patients do not tend to adhere to antihypertensive treatment. ${ }^{2}$

A total of $41(80.4 \%)$ of our study participants who adhered $<20 \%$ to the prescribed antihypertensive medications were male, showing a strong positive significant association ( $p=0.01$ ) between low adherence and gender.

There has been high variability reported for the rates of age-related adherence to therapy. Daniel and Veiga ${ }^{25}$ found that $54.9 \%$ of their subjects who had low adherence rates $(<20 \%)$ to treatment were in the age group of 51-60 years, and 32 of these patients in the age group of 51-60 years (30.5\%) had a medium adherence, demonstrating significant ( $p=0.0001)$ effects of age on treatment adherence. They also found that adherence to therapy was better in the age group of 40-59 years and those $>80$ years of age and that the most highly adherent participants were $61-70$ years old (31.4\%). In contrast, the current data are similar to those of Yang et a $\mathrm{l}^{12}$ from a Medicare cohort of 66-79-year-old subjects recently diagnosed with HTN that confirmed a better adherence to therapy compared to other age groups. Hansell et $\mathrm{a}^{28}$ assumed that, in elderly patients, cognitive impairment should also be considered as it may lead to problems with adherence to therapy, leading in some cases to improper use of the medications and also may lead to adverse outcomes or side effects from excessive lowering of BP by the use of these drugs. Marital status did not significantly influence the level of adherence to antihypertensive treatment $(p=0.06)$ in our cohort. In addition, the level of education did not significantly influence the level of adherence ( $p=0.11$ ).

A study conducted by Kamran et $\mathrm{al}^{29}$ in subjects living in rural environments showed low adherence (only 24\%) as a result of untoward perceptions, reduced awareness of complications, and low economic levels. Of 516 participants in our study group (active and deceased), we identified 55 patients living in rural areas versus 461 who resided in urban neighborhoods. When the data were examined, no statistically significant differences in levels of adherence to antihypertensive treatment were associated with these two types of residential areas.

Long-term monitoring of hypertensive populations in previous studies has demonstrated that good adherence to therapy is associated with significantly lower CV risk. ${ }^{12}$ Similar relationships between total CV risk and level of adherence were demonstrated in our study with a significant association within the active hypertensive subjects. The most non-adherent hypertensive patients had moderately elevated CV risk.

In our study, medication adherence level was influenced by the subject's comorbidities. The presence of CVD and CKD in our hypertensive subjects was associated with better adherence with treatment. Diabetic hypertensive patients did not have significantly higher adherence to 
antihypertensive treatment, but a nonsignificant ascendant tendency was found.

In a group of 527 hypertensive type 2 DM patients, Natarajan et $\mathrm{al}^{30}$ reported high adherence $(77 \%)$ in those aged 55 years and older, with more than seven prescribed drugs and maintenance of a healthy lifestyle. In Koreans, chronic disease management programs (DM and HTN) improved both the adherence and persistence of treatment. ${ }^{31}$ In addition, Putnam et $a l,{ }^{32}$ in a practice-based survey on hypertensive patients with type 2 diabetes achieved the target BP in 54\% of the cases, whereas patients with low adherence to therapy were less likely to achieve target BP levels.

Our data pointed to a strong influence on adherence to antihypertensive therapy by the presence of concomitant CVD. This relationship was observed in $79.4 \%$ of the subjects.

A study performed in Greece revealed that patients who viewed HTN as a chronic disease had a good doctor-patient relationship, were concerned about developing target organ damage, and were adherent to therapy. ${ }^{33}$

The results of our study confirm an association between low adherence and uncontrolled BP and emphasize the need for improved treatment strategies in hypertensive patients, because only $54.7 \%$ of our high adherence subjects were at target BP. The 2017 meta-analysis by Abegaz et $\mathrm{al}^{34}$ reported that although $45 \%$ of patients are non-adherent with treatment, a high proportion $(83.7 \%)$ of non-adherent patients have uncontrolled BP.

Although the modern pharmacopeia provides a broad array of efficient antihypertensive regimens, the occurrence of side effects still remains one of the main issues leading to non-adherence to therapy. Schoenthaler et $\mathrm{al}^{35}$ enhanced adherence in a cohort study of 92 patients treated with ACEI, assessed by an electronic monitoring device. In our study, $32.8 \%$ of the hypertensive patients undergoing treatment with ARBs were highly adherent (>80\%), suggesting a very strong association with high adherence using this class of agents noted for low side effect profiles. Interestingly, similarly strong adherence was noted in the current study with the use of ACEI, beta-blockers, and calcium channel blockers.

Monitoring adherence to antihypertensive therapy by analyzing drug concentrations or metabolites in plasma or urine is a feasible but expensive option. There are important perspectives on the potential use of biochemical screening for non-adherence to antihypertensive therapy. ${ }^{36,37}$

Administration of FDCs with minimal side effects may improve adherence and persistence to therapy without major cardiac events. ${ }^{38}$ In our study group, hypertensive patients receiving FDCs had significantly better adherence with clear evidence in 2014, probably encouraged by their wide use, as a direct consequence of relevant results in therapeutic and drug-monitoring studies. ${ }^{39}$

Ghembaza et $\mathrm{al}^{40}$ found that increased numbers of antihypertensive drugs prescribed in the presence of comorbidities are associated with poor adherence. However, the available evidence is not yet sufficient to conclude that there are differences between an FDC and to free combination therapy in the management of HTN. ${ }^{41}$

The extended period of this study (4 years) offered us the opportunity to note and analyze the effect of adjustments in antihypertensive treatment strategies. These changes within the same drug class were associated with high adherence, but higher adherence was noted if a change was made to prescribe a different drug class, and in this setting a psychological relationship could have been at play. Simplifying treatment is one of the easiest ways to increase adherence, but education and motivation are needed to achieve the desired outcome. ${ }^{42,43}$

Although the issue of medication adherence represents a challenge in antihypertensive treatment strategies, the persistence with antihypertensive therapy also needs to be considered. A retrospective cohort study by Veronesi et $\mathrm{al}^{44}$ found that hypertensive patients using ARBs have more treatment persistence. In addition, data from other studies show better persistence with ARBs and ACEI therapy compared to treatment with calcium channel blockers and beta-blockers. ${ }^{45,46}$ In our study, diuretics and ARBs showed a plateau in their usage rates over time, whereas calcium channel blockers had increased rates.

Even for patients aware of the potential impact of their HTN on their well-being, ongoing adherence with pharmacotherapy still represents a challenge for about half of them. A cross-sectional study carried out in Russia showed that BP control was maintained in $17 \%$ of patients out of $66 \%$ of patients with dual diagnoses of dyslipidemia and HTN who remained aware of their ongoing HTN diagnosis. ${ }^{47}$

In a study based on medical prescription claims carried out in nine communities in north-eastern Colorado, a high adherence level was found in hypertensive patients with dyslipidemia, and this resulted in reduced morbidity from CVD and stroke. ${ }^{9}$ In contrast, the present results in hypertensive patients with hypercholesterolemia in Romania, shows that only $46.9 \%$ were undergoing simultaneous lipid-lowering therapy. However, over the 4-year course of the study, an increasing rate of treatment with lipid-lowering agents was noted. 
In a meta-analysis of 22 studies performed worldwide, published between January 2000 and August 2015, Nielsen et $\mathrm{al}^{48}$ found that adherence rates to lipid therapy are not satisfactory in some low-to-middle-income countries. Our study comes from a low-to-middle-income country in Eastern Europe showing that in a population sample with medium and high levels of education there was a positive association with high adherence.

Good doctor-patient communication, adequate knowledge, awareness of the disease and its possible complications, as well as the use of special containers for drug dispensing (blister packs, bottles, and timed dosing batches), remembering to renew the prescriptions, and then affording the price of the medication are important elements that affect the adherence to the treatment plan. ${ }^{26,35,46}$

\section{Conclusion}

Currently, the most compelling evidence for improved management strategies for HTN is derived from evidencebased clinical trials utilizing well-identified patient profiles. However, the practice of clinical medicine requires the provider to apply those results to a real-world population incorporating personalized approaches to different subsets of patients, as defined by their medical status and also by their sociodemographic characteristics. The strength of this study rests on the use of extensive clinical data from our cohort, including information recorded on paper charts along with electronic records from our primary care system. This had the advantage of giving access to a widely used database that could be accessed easily and that can provide a tool for the assessment of adherence. The study targeted a geographical area where the prevalence of HTN has increased continuously. Our adherence assessment used a noninvasive, reliable, and accurate method to perform a prescription record review from a family practice-provider network. In this study, higher medication adherence rates were associated with gender (female), age (medium age and older patients), concomitant presence of CVD or risk factors, and CKD along with the achievement of good control of HTN. In our study, the patient's level of education appears to play an important role in enhancing the level of adherence.

Developing awareness and patient education could reduce the obstacles to implementing the strategies developed in this study at the personal level for appropriate patients. Moreover, if we can overcome the socioeconomic barriers typically occurring in the adult population that impede treatment of HTN, health care professionals may be able to improve the approach to the patient's problems and provide more effective therapy. The current results and analysis of our cohort study involving a relatively large number of participants in a single primary care center can provide resources for future BP management strategies that should enhance the health of hypertensive patients. The use of targeted, specific methods to assess adherence to short- and long-term treatment of HTN is crucial.

\section{Limitations}

The study has inherent limitations. As a single-center cohort study, it presents data from a middle-to-high-income area of Romania (a low-to-middle-income country). The level of adherence was estimated based on our evaluation of our catchment area which predominantly has an urban population. Therefore, the degree of education of the patients in our cohort was at a medium to high level and thus may not be representative of all the hypertensive patients in Romania.

\section{Acknowledgments}

Authors are thankful to all study participants, Dr Monica Marcela Puscas, Engineer Doina Cristea, Annamaria Gyorfi, and the other medical and administrative staff involved in family medicine activities at the clinics. This study was partially supported by the University of Medicine and Pharmacy of Tirgu Mures and Centrul Medical "Topmed” Tirgu Mures, Romania, Internal Research Grant 6850/15.06.2015.

\section{Author contributions}

Ioan Tilea made major contributions to conception and design and systematization and interpretation of data and approved the final version of the manuscript to be published. Dorina Petra performed substantial contributions to conception, literature review, and drafting of the manuscript and approved the final version of the manuscript to be published. Septimiu Voidazan performed significant contributions to statistical analysis data judgment drafting reviewing of the manuscript and approved the final version of the manuscript to be published. Elena Ardeleanu prepared the manuscript, adjusted it critically for important intellectual content, and approved the final version of the manuscript to be published. Andreea Varga performed major contributions to manuscript formulation and design, acquisition, systematization, and interpretation of data, reviewed the manuscript for intellectual content, and approved the final version of the manuscript to be published.

\section{Disclosure}

The authors report no conflicts of interest in this work. 


\section{References}

1. Mills KT, Bundy JD, Kelly TN, et al. Global disparities of hypertension prevalence and control a systematic analysis of population-based studies from 90 countries. Circulation. 2016;134(6):441-450.

2. Dorobantu M, Darabont R, Ghiorghe S, et al. Hypertension prevalence and control in Romania at a seven-year interval. Comparison of SEPHAR I and II surveys. J Hypertens. 2014;32:39-47.

3. Dorobantu M, Darabont R, Dimulescu D, et al. New epidemiologic national representative survey: SEPHAR III - main results. J Hypertens. 2017;35:e60.

4. Dorobantu M, Tautu OF, Dimulescu D, et al. Perspectives on hypertension's prevalence, treatment and control in a high cardiovascular risk East European country: data from the SEPHAR III survey. J Hypertens. 2017;35(1):1-11.

5. Walther D, Curjuric I, Dratva J, et al. High blood pressure: prevalence and adherence to guidelines in a population-based cohort. Swiss Med Wkly. 2016;146:w14323.

6. Cushman WC, Whelton PK, Fine LJ, et al. SPRINT trial results: latest news in hypertension management. Hypertension. 2016;67(2):263-265.

7. Schiffrin EL. The year in clinical hypertension from other pages. Am J Hypertens. 2018;31(2):136-138.

8. Herttua K, Tabák AG, Martikainen P, Vahtera J, Kivimäki M. Adherence to antihypertensive therapy prior to the first presentation of stroke in hypertensive adults: population-based study. Eur Heart J. 2013;34(38): 2933-2939.

9. Oung AB, Kosirog E, Chavez B, Brunner J, Saseen JJ. Evaluation of medication adherence in chronic disease at a federally qualified health center. Ther Adv Chronic Dis. 2017;8(8-9):113-120.

10. Mekonnen HS, Gebrie MH, Eyasu KH, Gelagay AA. Drug adherence for antihypertensive medications and its determinants among adult hypertensive patients attending in chronic clinics of referral hospitals in Northwest Ethiopia. BMC Pharmacol Toxicol. 2017;18(1):27.

11. Mancia G, Zambon A, Soranna D, Merlino L, Corrao G. Factors involved in the discontinuation of antihypertensive drug therapy: an analysis from real life data. J Hypertens. 2014;32(8):1708-1715.

12. Yang Q, Chang A, Ritchey MD, Loustalot F. Antihypertensive medication adherence and risk of cardiovascular disease among older adults: a population-based cohort study. J Am Heart Assoc. 2017;6(6):e006056.

13. Pirasath S, Kumanan T, Guruparan M. A study on knowledge, awareness, and medication adherence in patients with hypertension from a tertiary care centre from northern Sri Lanka. Int J Hypertens. 2017;2017:9656450.

14. Bharti S, Bharti B. Adherence to antihypertensive therapy: a missing link between treatment and outcomes. Am J Hypertens. 2017;31(3): 290-292.

15. Vrijens B, Antoniou S, Burnier M, de la Sierra A, Volpe M. Current situation of medication adherence in hypertension. Front Pharmacol. 2017;8:100.

16. Parati G, Omboni S, Compare A, et al. Blood pressure control and treatment adherence in hypertensive patients with metabolic syndrome: protocol of a randomized controlled study based on home blood pressure telemonitoring vs. conventional management and assessment of psychological determinants adherence (TELEBPMET Study). Trials. 2013; $14: 22$.

17. Frias J, Virdi N, Raja P, Kim Y, Savage G, Osterberg L. Effectiveness of digital medicines to improve clinical outcomes in patients with uncontrolled hypertension and type 2 diabetes: prospective, openlabel, cluster-randomized pilot clinical trial. J Med Internet Res. 2017; 19(7):e246.

18. Jankowska-Polańska B, Uchmanowicz I, Dudek K, Mazur G. Relationship between patients' knowledge and medication adherence among patients with hypertension. Patient Prefer Adherence. 2016;10: 2437-2447.

19. Fortuna RJ, Nagel AK, Rocco TA, Legette-Sobers S, Quigley DD. Patient experience with care and its association with adherence to hypertension medications. Am J Hypertens. 2017;31(3):340-345.
20. Hedegaard U, Kjeldsen LJ, Pottegard A, et al. Improving medication adherence in patients with hypertension: a randomized trial. Am J Med. 2015;128(12):1351-1361.

21. Mancia G, Fagard R, Narkiiewicz K, et al. 2013 ESH/ESC Guidelines for the management of arterial hypertension. The Task Force for the management of arterial hypertension of the European Society of Hypertension (ESH) and of the European Society of Cardiology (ESC). Eur Heart J. 2013;34:2159-2219.

22. O'Brien E, Atkins N, Stergiou G, et al; for Working Group on Blood Pressure Monitoring of the European Society of Hypertension. European society of hypertension international protocol revision 2010 for the validation of blood pressure measuring devices in adults. Blood Press Monit. 2010;15:23-38.

23. Alhalaiqa F, Al-Nawafleh A, Batiha AM, Masa'Deh R, Al-Razek AA. A descriptive study of adherence to lifestyle modification factors among hypertensive patients. Turk J Med Sci. 2017;47:273-281.

24. Boima V, Ademola AD, Odusola AO, et al. Factors associated with medication nonadherence among hypertensives in Ghana and Nigeria. Int J Hypertens. 2015;2015:205716. [Epub 2015 Oct 5].

25. Daniel AC, Veiga EV. Factors that interfere the medication compliance in hypertensive patients. Einstein (Sao Paulo). 2013;11(3):331-337.

26. Karakurt P, Kasikci M. Factors affecting medication adherence in patients with hypertension. J Vasc Nurs. 2012;30(4):118-126.

27. Tibebu A, Mengistu D, Bulto LN. Adherence to prescribed antihypertensive medications and associated factors for hypertensive patients attending chronic follow-up units of selected public hospitals in Addis Ababa, Ethiopia. Int J Health Sci (Qassim). 2017;11(4):47-52.

28. Hansell MW, Mann EM, Kirk JK. Hypertension treatment strategies for older adults. J Fam Pract. 2017;66(9):546-554.

29. Kamran A, Sadeghieh Ahari S, Biria M, Malepour A, Heydari H. Determinants of patient's adherence to hypertension medications: application of health belief model among rural patients. Ann Med Health Sci Res. 2014;4(6):922-927.

30. Natarajan N, Putnam W, Van Aarsen K, Beverly Lawson K, Burge F. Adherence to antihypertensive medications among family practice patients with diabetes mellitus and hypertension. Can Fam Physician. 2013;59(2):e93-e100.

31. Kim JA, Kim ES, Lee EK. Evaluation of the chronic disease management program for appropriateness of medication adherence and persistence in hypertension and type-2 diabetes patients in Korea. Medicine (Baltimore). 2017;96(14):e6577.

32. Putnam W, Lawson B, Buhariwalla F, et al. Hypertension and type 2 diabetes: what family physicians can do to improve control of blood pressure - an observational study. BMC Fam Pract. 2011;12:86.

33. Tsiantou V, Pantzou P, Pavi E, Koulierakis G, Kyriopoulos J. Factors affecting adherence to antihypertensive medication in Greece: results from a qualitative study. Patient Prefer Adherence. 2010;4:335-343.

34. Abegaz TM, Shehab A, Gebreyohannes EA, Bhagavathula AS, Elnour AA. Nonadherence to antihypertensive drugs. A systematic review and meta-analysis. Medicine (Baltimore). 2017;96(4):e5641.

35. Schoenthaler A, Knafl GJ, Fiscella K, Ogedegbe G. Addressing the social needs of hypertensive patients: the role of patient-provider communication as a predictor of medication adherence. Circ Cardiovasc Qual Outcomes. 2017;10(9):e0003659.

36. Jones ESW, Lesosky M, Blockman M, et al. Therapeutic drug monitoring of amlodipine and the Z-FHL/HHL ratio: Adherence tools in patients referred for apparent treatment-resistant hypertension. $S$ Afr Med J. 2017;107(10):887-891.

37. Gupta P, Patel P, Štrauch B, et al. Biochemical screening for nonadherence is associated with blood pressure reduction and improvement in adherence. Hypertension. 2017;70(5):1042-1048.

38. Tung YC, Huang YC, Wu LS, Chang CJ, Chu PH. Medication compliance and clinical outcomes of fixed-dose combinations vs free combinations of an angiotensin II receptor blocker and a calcium channel blocker in hypertension treatment. J Clin Hypertens (Greenwich). 2017; 19:983-989. 
39. Varga A, Farczádi L, Vlase L, Primejdie DP, Carasca E, Tilea I. Liquid chromatography tandem mass spectrometry simultaneous determination of amlodipine and telmisartan in human plasma for therapeutic drug monitoring. Rev Chim (Bucharest). 2015;66(10):1675-1679.

40. Ghembaza MA, Senoussaoui Y, Tani MK, Meguenni K. Impact of patient knowledge of hypertension complications on adherence to antihypertensive therapy. Curr Hypertens Rev. 2014;10:41-48.

41. Mallat SG, Tanios BY, Itani HS, Lotfi T, Aki EA. Free versus fixed combination antihypertensive therapy for essential arterial hypertension: a systematic review and meta-analysis. PLoS One. 2016;11(8):e0161285.

42. Lee HJ, Jang SI, Park EC. Effect of adherence to antihypertensive medication on stroke incidence in patients with hypertension: a populationbased retrospective cohort study. BMJ Open. 2017;7(6):e014486.

43. Bourgault C, Senecal M, Brisson M, Marentette MA, Gregoire JP. Persistence and discontinuation patterns of antihypertensive therapy among newly treated patients: a population-based study. J Hum Hypertens. 2005;19(8):607-613.
44. Veronesi M, Cicero AF, Prandin MG, et al. A prospective evaluation of persistence on antihypertensive treatment with different antihypertensive drugs in clinical practice. Vasc Health Risk Manag. 2007;3(6): 999-1005.

45. Simons LA, Ortiz M, Calcino G. Persistence with antihypertensive medication: Australia-wide experience, 2004-2006. Med J Aust. 2008; 188(4):224-227.

46. Abbas H, Kurdi M, Watfa M, Karam R. Adherence to treatment and evaluation of disease and therapy knowledge in Lebanese hypertensive patients. Patient Prefer Adherence. 2017;11:1949-1956.

47. Cybulsky M, Cook S, Kontsevaya AV, Vasiljev M, Leon DA. Pharmacological treatment of hypertension and hyperlipidemia in Izhevsk, Russia. BMC Cardiovasc Disord. 2016;16:122.

48. Nielsen JØ, Shrestha AD, Neupane D, Kallestrup P. Non-adherence to anti-hypertensive medication in low- and middle-income countries: a systematic review and meta-analysis of 92443 subjects. J Hum Hypertens. 2017;31(1):14-21.

\section{Publish your work in this journal}

Patient Preference and Adherence is an international, peer-reviewed, open access journal that focuses on the growing importance of patient preference and adherence throughout the therapeutic continuum. Patient satisfaction, acceptability, quality of life, compliance, persistence and their role in developing new therapeutic modalities and compounds to optimize clinical outcomes for existing disease states are major areas of interest for the journal. This journal has been accepted for indexing on PubMed Central. The manuscript management system is completely online and includes a very quick and fair peer-review system, which is all easy to use. Visit http://www. dovepress.com/testimonials.php to read real quotes from published authors.

Submit your manuscript here: http://www.dovepress.com/patient-preference-and-adherence-journal 